\title{
10 The role of private health insurance in financing health care in Kenya
}

\author{
DAVID MUTHAKA
}

Kenya has a pluralistic health system, with the government, private actors and donors involved in the financing and provision of health care. Since the late 1980s, the government has encouraged private investment in health care and there is now a large and diverse private health care delivery sector comprising for-profit and non-profit facilities. The growth of private provision has in turn created demand for private health insurance. Private health insurance cover is mainly purchased by higher-income employees in urban areas and only covered under $2 \%$ of the population in 2013 (Ministry of Health, 2014). It is beyond the financial reach of most of the population in a country plagued by poverty and income inequality, where access to affordable health care depends not just on the availability of funds but also on the availability of health workers and facilities. Until 2006, health insurers operated in an unregulated environment and there have been issues with fraud. The chapter begins with an overview of health financing policy in Kenya, then outlines the nature of the private health insurance market, the regulatory framework and barriers to market expansion.

\section{Health financing policy}

\section{The public-private mix in financing and delivery}

Health financing policy has undergone several changes since Kenya gained independence in 1963 . Health care was virtually free in the 1960s and 1970s, but a severe economic decline forced the government to initiate a cost-sharing programme for health services and education in 1989 as part of the conditionality imposed by Structural Adjustment Programmes in return for loans from the World Bank and the International Monetary Fund. The new programme substantially expanded the modest fees that had been charged in government hospitals and health centres. Alongside reforms to relax licensing and other 
regulatory requirements, the programme was intended to create an environment conducive to greater private sector involvement (Muthaka et al., 2004).

Limited government resources led to deterioration in public health care services. Households turned to private clinics, pharmacies and traditional healers to obtain health care and private provision began to grow. In 1999, private health facilities accounted for $48 \%$ of all health facilities, but by 2006 their share had risen to $59 \%$, falling to $49 \%$ in 2014 (Ministry of Health, 2007, 2013; Government of Kenya, 2010). Nevertheless, bed capacity is still higher in the public sector, because public facilities are on average larger than private ones. In early 2010, about $60 \%$ of all beds were in the public sector.

In 2012/2013, public spending on health accounted for $34 \%$ of total health expenditure, donor funding for $19 \%$ and households (out-ofpocket payments) for $29 \%$ (Ministry of Health, 2015a). Public funding comes from government budget allocations to the Ministry of Health and related government organizations such as the National AIDS Control Council. However, given the economic situation and other factors, budget transfers have not been an adequate source of health financing. Privately provided services are financed through out-of-pocket payments and private health insurance premiums. Out-of-pocket payments are the second largest single source of health care financing after government spending.

Between 2001/2002 and 2012/2013, total expenditure on health accounted for well below $10 \%$ of gross domestic product (see Table 10.1). Government expenditure on health averaged around $6 \%$ of total government expenditure over the same decade, much less than the Abuja commitment of $15 \%$ and despite the various challenges Kenya faces, such as poor health indicators and increasing high burden of noncommunicable and emerging diseases. However, owing to sustained levels of financing coming from households and development partners, total per person health expenditure rose from US\$45 in 2001/2002 to US\$67 in 2012/2013 (Ministry of Health, 2015b).

\section{Cost-sharing revenues}

The cost-sharing programme introduced in 1989 was devised as a way of generating more revenue for the health sector (Kimalu et al., 2004). However, funds raised through this programme are usually retained 


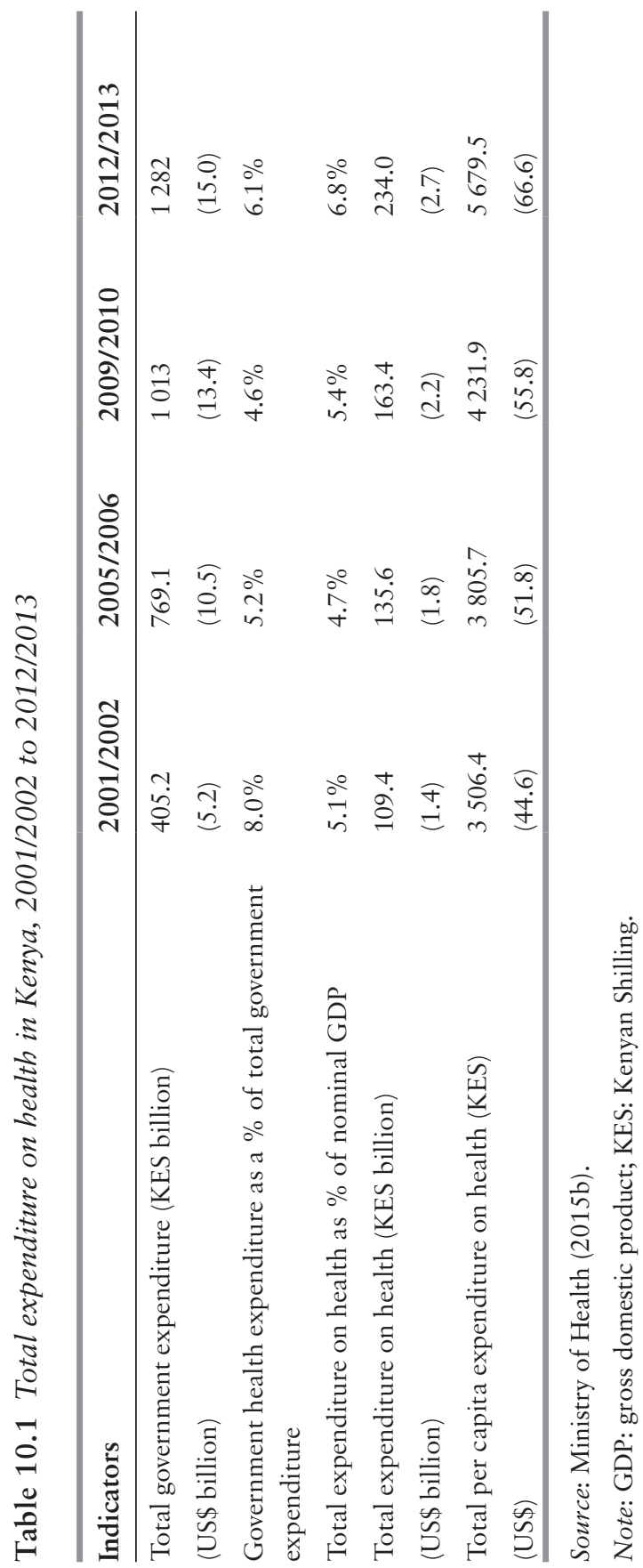



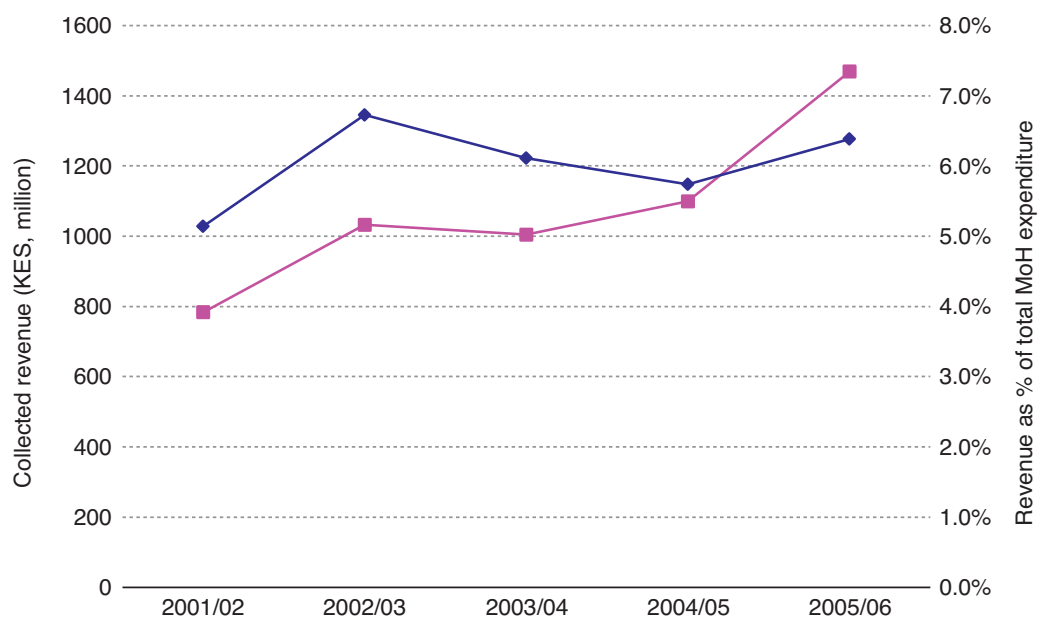

Figure 10.1 Cost-sharing revenue as a share (\%) of total expenditure of Kenyan Ministry of Health, 2001/2002 to 2008/2009

Source: Author's compilation based on data from the Ministry of Health (2007) and the Government of Kenya (2010).

by health facilities to boost their recurrent budgets and, as a result, they account for less than $10 \%$ of Ministry of Health expenditure (see Fig. 10.1). The decline in cost sharing as a share of Ministry of Health spending observed after 2002/2003 can be attributed to growth in the Ministry's budget and changes in cost-sharing policy, which also coincided with a change in political leadership in the country. In 2004 , in response to growing poverty levels ${ }^{1}$ (Kenya National Bureau of Statistics, 2007), the Ministry adopted a 10/20 policy, according to which dispensaries and health centres were to forfeit fees for curative health care and instead only charge a registration fee of 10 Kenyan

${ }^{1}$ According to the 2005/2006 Kenya Integrated Household and Budget Survey, which is the latest household survey in Kenya, the absolute poverty level in the rural population was estimated to be $49.1 \%$ and the national poverty level for the extremely poor (whose income does not suffice to buy the required daily calorific intake even if it was entirely devoted to purchasing food) was estimated to be $21.9 \%$ (Kenya National Bureau of Statistics, 2007). The Kenya Economic Report (2010) published by the government think tank, Kenya Institute for Public Policy Research and Analysis (KIPPRA) projected an increase in the rural poverty level to $53.4 \%$ in 2012 (KIPPRA, 2010). 
shillings (KES) (US\$0.15) and KES20 (US\$0.30) respectively, payable on every visit. However, many facilities charged more than these token fees citing inadequate government funding and the resulting inability to cover their financial needs (Onsomu et al., 2014). After health care was fully devolved to county (regional) governments in 2013, the Kenya Health Policy 2014-2030 abolished all user charges in dispensaries and health centres.

\section{National Hospital Insurance Fund contributions}

Besides using tax revenues and cost sharing, the Ministry of Health has continued to promote the National Hospital Insurance Fund (NHIF), with plans to turn it into a universal health insurance scheme. The NHIF was established in 1966 under Chapter 255 of the Laws of Kenya to be run by an advisory council appointed by the Minister of Health. In 1998, the 1966 Act was repealed and replaced by the NHIF Act of 1998, which established the fund as an autonomous state corporation "to provide for a national contributory hospital insurance scheme for all residents", replacing the then existing racial insurance schemes. Enrolment in the NHIF is mandatory for all formally employed workers and voluntary for the self-employed, unemployed and those working in the informal sector. In 2015, the NHIF replaced the monthly flat rate contributions for those in formal employment with income-dependent contributions based on gross salary. Contributions range from KES150 to KES1700 per month (NHIF, 2016). At the same time, and for the first time since its establishment, the NHIF also introduced coverage for outpatient benefits, thereby offering comprehensive medical cover. ${ }^{2}$ The NHIF-covered services can be accessed in the majority of accredited government facilities, mission health care providers and in some low-cost private health care providers across the country (together, over 400 facilities). No additional user charges are levied on these services. The NHIF cover also includes inpatient services in high-cost private hospitals, but patients using these facilities face user charges due to the high level of fees charged (the NHIF cover does not suffice).

2 The NHIF cover also includes a comprehensive maternity package. Such care can be accessed in government hospitals, in the majority of mission hospitals and in some private hospitals. 
Before 2008, almost half of the funds collected by the NHIF (on average $48 \%$ ) were used to cover administrative expenses, with only a third (on average $33.5 \%$ ) being used to reimburse health care costs. This improved between 2008/2009 and 2014/2015, with more funds from contributions used for provision of benefits in that period (Table 10.2). Nevertheless, various challenges prevent the NHIF from becoming a successful risk-sharing scheme, including poor governance and management, lack of control over lengths of stay and uncontrolled growth in the number of facilities. The latter has led to a rapid expansion of both legitimate and fraudulent claims, but the number of accredited facilities is still limited and unevenly distributed, which means access to health care may be difficult, particularly in rural areas.

In light of the challenges faced by the NHIF since its establishment, in the early 2000s the government proposed transforming the NHIF into a National Social Health Insurance Scheme (NSHIS) that would be compulsory for all Kenyans and permanent residents and involve a government subsidy for the poor. In addition to correcting the failures of the NHIF, the proposed scheme would address fundamental concerns regarding equity, access, affordability and quality in the provision of health services to the poor. However, the proposed scheme was opposed by health insurance companies, private health care providers and development partners, including the World Bank and the International Monetary Fund. Health insurers feared they would lose business if the scheme was successfully implemented and private providers, including health management organizations (HMOs), feared they would lose customers if public health facilities were improved. Development partners were against the scheme on the basis that it would require more resources than a country of Kenya's economic status could sustain (Consumer Information Network, 2006). The reliability of NSHIS funding was questioned given that the country's formal sector was very small (about two million people out of 39.4 million) and $45.9 \%$ of the population was below the national poverty line. This meant that not enough resources could be generated by taxing those in formal employment. Also, the proposed $2.9 \%$ earmarked income tax for employees, matched by the same amount paid by employers, was viewed as too high a burden to both. Employees who benefited from private health insurance financed by employers feared that the latter would cease 


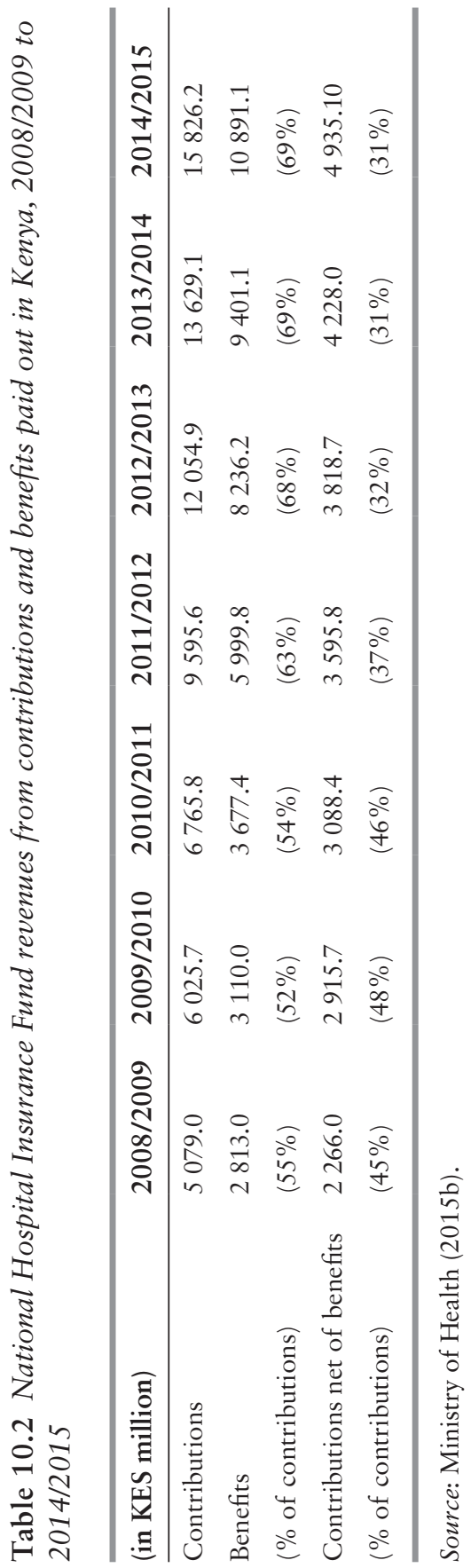


offering private cover ${ }^{3}$ when faced with extra NSHIS charges, and that if the costs to employers were too high, they would lower wages or reduce employment. The Ministry of Finance was concerned that the government, as the key employer in the formal sector, would be forced to bear most of the financing burden by paying contributions for civil servants. Thus, meeting the proposed scheme's estimated cost of between KES40 billion to KES70 billion ${ }^{4}$ was viewed as unrealistic. Other fundamental issues concerned the scheme's ability to improve access, quality and affordability of care. It was acknowledged that improved access to health care could not be achieved unless the Ministry of Health ensured expansion of health infrastructure to rural areas, where $75 \%$ of the population lives. ${ }^{5}$ As a result, the proposal was first watered down from a mandatory scheme to a voluntary one and eventually never implemented.

According to WHO estimates, as of $2015,55 \%$ of private health expenditure was paid out of pocket, while $16 \%$ was attributable to private health insurance. The remaining $30 \%$ was financed from other sources such as non-profit institutions (Fig. 10.2). Expenditure on private health insurance has been relatively stagnant for a long time. In 1995 , it accounted for $4.4 \%$ of total health expenditure and $7.6 \%$ of private sector expenditure. It then declined to $6.8 \%$ of private health expenditure in 2002. In that year, $74 \%$ of premiums were paid by households, $24 \%$ by private employers and the remaining $2 \%$ by government agencies (Ministry of Health, 2005). Since then there has been some growth in private health insurance expenditures as shown in Fig. 10.2.

\section{The role and growth of private health insurance}

\section{Market origins and expansion}

Private health insurance first emerged following the government's call for private sector participation in health care provision in the 1980s and

${ }^{3}$ Compared to the NHIF, private health insurance is more expensive but offers better quality of services.

4 This is approximately US\$394 million to US\$690 million at an exchange rate of US\$1 to KES101.5 in 2016.

5 The same argument could be applied to health workers, who are also concentrated in urban areas. 


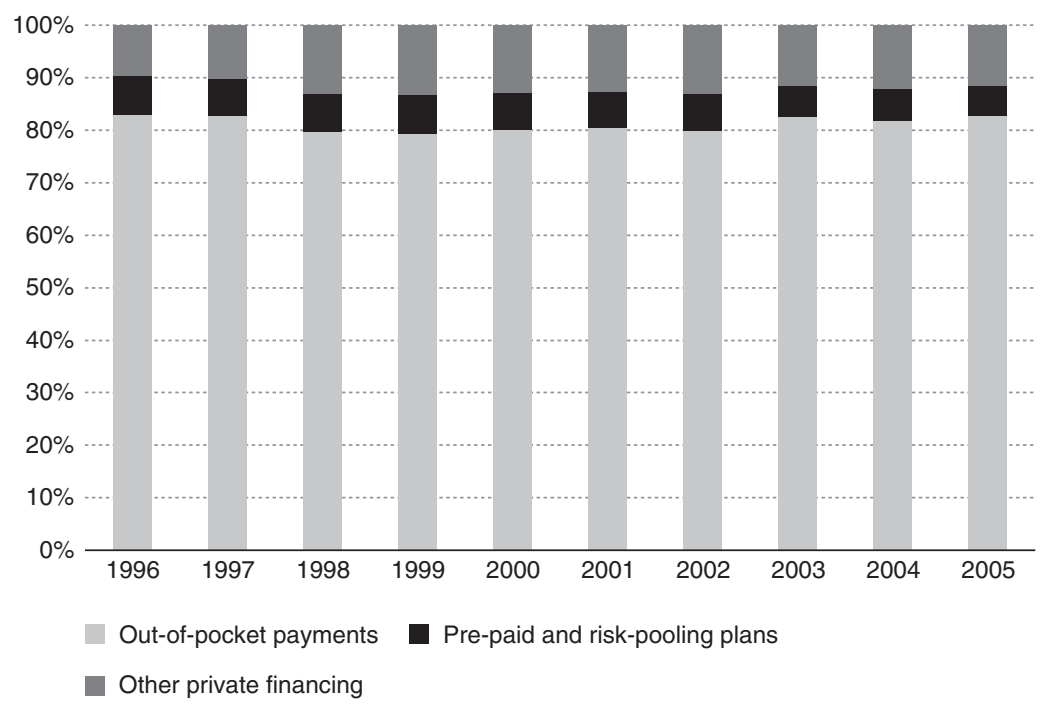

Figure 10.2 Breakdown of private expenditure on health in Kenya, 20042015.

Source: WHO (2018).

1990s and the market's expansion was initially closely associated with the development of private health facilities. The government relaxed regulations governing private practice, allowed health professionals to work in both the public and the private sectors and granted them permission to set up their own clinics. The government's cost-sharing policy, introduced at the same time, prompted people to seek care in the private sector as the quality of care in public facilities deteriorated due to limited funding. Demand for private health insurance was further stimulated by employers offering private health insurance as an employee benefit to attract better workers, reduce absenteeism and increase productivity.

In response to this rising demand, general insurance companies developed policies covering medical benefits, initially only selling them to companies as corporate or group cover because individuals were not regarded as reliable customers. In 1999 , about $87 \%$ of private health insurance policies were purchased by companies for their employees (Ministry of Health, 1999). Other types of insurers also emerged, notably HMOs and medical insurance providers. For example, the Africa Air 
Rescue Health Services, a privately owned Kenyan HMO, was established in 1984 as an emergency rescue company and began to provide comprehensive health services in 1991 (Chee \& Tharmaratnam, 1997), while MediPlus, a privately owned medical insurance provider, was founded in 1996 through a network of independently owned health service providers operating throughout the country (McCord \& Osinde, 2002). Increased competition within the insurance industry contributed to growth in the private health insurance market.

\section{Take-up of private health insurance}

According to Ministry of Health data (Ministry of Health, 2003), $9.7 \%$ of the population had some form of health insurance in 2003 . The NHIF was the largest single provider of health insurance $(88.1 \%$ of the insured population), followed by group private health insurance $(6.3 \%)$, individual private health insurance $(5.0 \%)$ and other sources, including community insurance $(0.6 \%)$. This means that in 2003 only about $1.1 \%$ of the population (353 000 people) was covered by private health insurance. By 2007, NHIF coverage had declined to $83.8 \%$ of the insured, group private health insurance increased to $12.0 \%$, individual private health insurance to $7.9 \%$ and other sources to $1.1 \%$ (Ministry of Health, 2009). By 2013, the share of those insured through NHIF increased to $88.4 \%$; private health insurance covered $9.4 \% ;^{6}$ community-based insurance $1.3 \%$; and other forms of insurance $1.0 \%$ (Ministry of Health, 2014). The increase in NHIF's coverage can be associated with improvements in NHIF's functioning, including enhanced benefits coverage, and successful campaigns promoting public awareness of NHIF benefits, which increased coverage in the informal sector.

Private health insurance is mainly purchased by the non-poor, the employed and urban residents. Health insurers tend to be based in or focus on urban areas; most urban residents have regular incomes from employment or self-employment (including small-scale or informal

${ }^{6}$ It has to be noted that contrary to earlier household surveys, the 2013 survey did not include the question about the possession of group insurance (it only asked whether the respondent had private health insurance cover, without distinguishing between individual and group cover). This means that there may have been some double counting for people who had both individual and group covers in the previous surveys. 
Table 10.3 Distribution of insured people by the type of health insurance coverage and region in Kenya, 2013

\begin{tabular}{lccll}
\hline & NHIF & $\begin{array}{l}\text { Private health } \\
\text { insurance }\end{array}$ & $\begin{array}{l}\text { Community } \\
\text { insurance }\end{array}$ & Other \\
\hline Nairobi & 76.60 & 22.20 & 0.30 & 0.80 \\
Central & 85.80 & 8.94 & 3.68 & 1.62 \\
Coast & 92.03 & 6.83 & 0.38 & 0.77 \\
Eastern & 93.29 & 4.44 & 1.53 & 0.76 \\
Nyanza & 96.10 & 2.75 & 0.47 & 0.70 \\
Rift Valley & 93.16 & 5.74 & 0.61 & 0.51 \\
Western & 92.25 & 5.43 & 1.33 & 1.00 \\
\hline
\end{tabular}

Source: Ministry of Health (2014).

Notes: Figures show percentages of total population in a given region. NHIF:

National Hospital Insurance Fund.

businesses); they are generally better educated than rural residents and therefore have access to more information on private health insurance. Having private health insurance is regarded as a symbol of higher social status. Household survey data from 2013 indicate that private health insurance take-up is $26.6 \%$ among urban residents, $12.1 \%$ among rural residents, $16 \%$ among those in the highest income quintile, $3.3 \%$ in the middle quintile and $3.6 \%$ in the lowest quintile (Ministry of Health, 2014). It is therefore evident that the number of rural poor people with private cover is very small. What is more, even this small number may in fact represent the dependants of those who are employed and privately insured or those who are covered through the NHIF.

As shown in Table 10.3, the government's NHIF has the widest coverage in all regions among the insured population. This is not surprising given that it is mandatory for formal employees and covers their dependants as well. ${ }^{7}$ Population coverage of private health insurance is very low in all regions and stands at less than $10 \%$ across the country (see above). The exception is Nairobi, where roughly one in every four

7 The average household size for Kenya is about six people. With 2 million people in formal employment, this means that around 12 million people were covered for inpatient care through the NHIF (NHIF's cover was only extended to outpatient care in 2015). 
citizens has private health insurance cover. Individual private health insurance has very low penetration rates in all regions, with some regions having less than $2 \%$ of their populations covered by this type of insurance.

\section{Types of private health insurance provider}

In 2015, there were 51 general and life insurance companies, 22 medical insurance providers (MIPs). There were also 144 insurance brokers and 6428 insurance agents (AKI, 2016). Nineteen of the 51 general insurers offer health insurance policies (see Table 10.4). Before the amendment of the Insurance Act in 2006, some MIPs provided health care through their own facilities (the HMOs) or through third-party facilities. As the HMOs only used their own doctors and facilities, their premiums were often low in comparison with other private insurers and this made them especially popular with employers who offered private health insurance cover to their employees. ${ }^{8}$ When the 2006 amendment came into force, the MIPs restructured their operations to separate medical insurance and health care provision. As a result, there are no more HMOs operating in the market and the MIPs are exclusively focused on health insurance business, contracting health service provision from private doctors and hospitals.

\section{Types of private health insurance cover}

There are two main types of cover: individual cover and group cover. For both sorts of cover, contracts are normally renewed annually and premiums are paid once a year. Only a few insurers offer individual cover. People can choose from varying levels of cover and premiums are usually age related. Some insurers have discontinued individual cover due to moral hazard issues and cases of fraudulent behaviour in which enrollees would falsify information in order to obtain medical treatment for friends and family members who were not covered. However, as the health insurance market opens up and becomes more competitive, the scenario is changing and insurers have introduced measures to

${ }^{8}$ However, the geographical coverage of their service providers was not as wide as it was for other insurers, so access to health care was probably lower for HMO members. 
protect themselves from fraud and moral hazard. For example, some use biometric measures to verify membership (for example, Resolution Health and UAP Insurance). Others have introduced cost sharing and restrictions regarding pre-existing conditions (waiting periods); most enrol children only after a 1-month waiting period; some require annual medical examinations from enrollees above 60 years old and do not enrol new members over 60 years old.

Most insurers offer cover to corporate and non-corporate groups (including families) of at least 10 individuals, usually tailored to the specific needs of a group. Employers who offer cover to their employees often work closely with insurers to develop plans and set annual uniform limits for each employee. Some of them opt to cover inpatient care only (basic cover), while others develop more comprehensive plans, covering both inpatient and outpatient care and other supplementary benefits, such as dental and optical care. Most corporate plans cover employees' dependants as well. Employees sometimes negotiate private health insurance cover for themselves and their dependants.

The most common methods of paying providers are so-called credit facilities and fee-for-service (see Table 10.4). The former is offered by most medical insurance providers, which makes health care services more accessible (enrollees receive benefits-in-kind). General insurers typically require that enrollees pay providers up front on a fee-for-service basis and claim reimbursement by submitting claims. Reimbursement policies are not popular among corporate clients.

\section{Public policy towards private health insurance}

The government is mandated to facilitate and regulate the provision of health care to all citizens. The legal framework covering general and health insurance can be found in the 2006 Insurance Amendment Act, the National Hospital Insurance Fund Act (No. 9 of 1998), which affects private providers because the NHIF contracts them to provide services to its members, and the Medical Practitioners and Dentists Act, Chapter 253 of the Laws of Kenya.

Before 2006, the Insurance Act had no provisions relating to health insurance. At the same time, there was a large number of health insurance providers operating in the private sector whose operations were not regulated by the law. For instance, HMOs were not required to register 


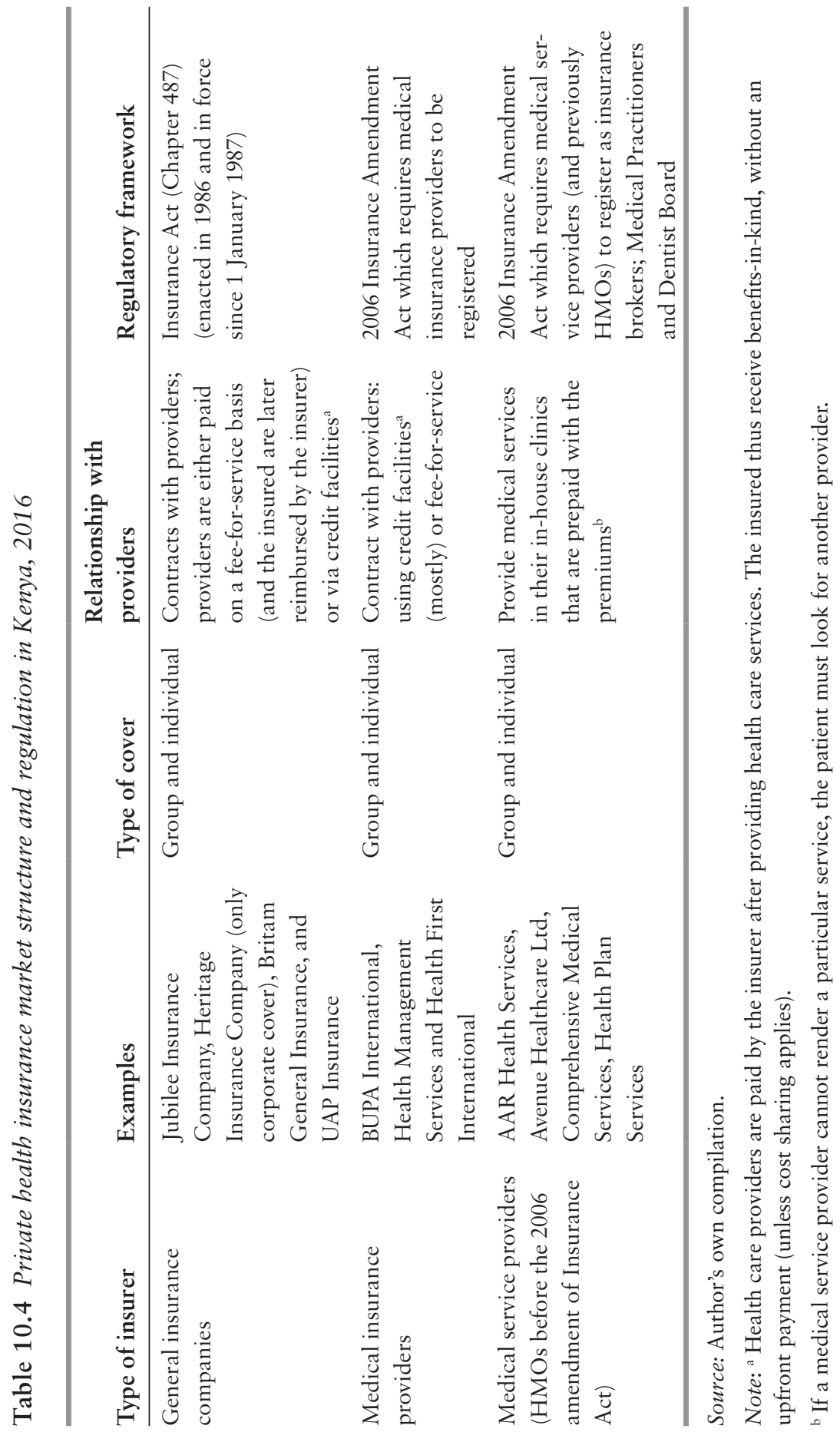


with the Commissioner of Insurance as medical insurance providers (and their operations were therefore not controlled) and the medical insurance providers were not insurance brokers under the Insurance Act. Also, the professional qualifications of the insurance brokers were not considered important or not considered at all during registration and the brokers were not required to register with the Insurance Office of the Commissioner of Insurance (companies registered under the Company's Act, Chapter 486 of the Laws of Kenya could provide insurance if this was stated in their memorandum of association).

Before 2006, there was no regulation for specialist medical insurance companies. Consequently, MIPs did not come under general insurance regulations and only had to register as private companies under the Companies Act (Chapter 486 of the Laws of Kenya). In the 1990s, some MIPs collapsed due to challenges such as weak management structures, moral hazard and financial liquidity problems resulting from the absence of capital requirements (solvency margins). Research into one MIP, MediPlus, before it ceased operations in 2003 concluded that between 2000 and 2001 its so-called trade payables (payments to clinics and hospitals) had increased by $308 \%$ but its total premiums had only increased by $98 \%$ (McCord \& Osinde, 2002: p.11). One possible cause of this liquidity problem was the lack of provisions to minimize adverse selection; for example, MediPlus did not require whole families to enrol (McCord \& Osinde, 2002). HMOs also operated in an unregulated environment for a number of years (Muthaka et al., 2004) and were only required to register under the Companies Act and the Medical Practitioners and Dentists Act (Chapter 253).

The Insurance Amendment Act of 2006 aimed to strengthen the regulatory framework for MIPs. The Insurance Regulatory Authority was established and MIPs were required to register with it and meet certain capital requirements, and capital requirements for insurance companies were increased. To avoid any conflict of interests, medical insurance providers were no longer allowed to provide medical care services but instead had to rely on third-party providers.

The Insurance Amendment Act, the main law regulating the insurance market, applies to general insurance companies, MIPs and medical services providers (also known as HMOs). Only people or bodies registered under the Act can participate in the insurance market and do so only for the class or classes of insurance products indicated in their Articles and Memoranda of Association at the point of registration as 
corporate entities (under the Companies Act, Chapter 486 of the Laws of Kenya). Applicants have to meet requirements regarding adequacy of assets, capital, reinsurance arrangements and staff. To protect consumers against high premiums and insolvency, the government requires insurance companies to present to the registration board indications of their premiums and methods of calculation as well as examples of policy forms, terms and conditions.

The Insurance Amendment Act (2006) of the Laws of Kenya also transformed the Department of Insurance into an autonomous supervisory authority through the creation of an independent Insurance Regulatory Authority that replaced the Office of the Commissioner of Insurance. The function of the Insurance Regulatory Authority is to supervise and regulate the insurance sector by formulating and enforcing standards of conduct, protecting the interests of the insured and advising the government on policies to protect the sector (Section 3A, Insurance Amendment Act 2006). The Commissioner of Insurance has the right to inspect the activities of insurance companies, which acts as a deterrent to unscrupulous or unethical practices.

The HMOs used to be registered as companies under the Companies Act, Chapter 486 of the Laws of Kenya. From 2006, however, they also had to register with and apply the provisions of the Insurance Amendment Act, which classified them as brokers. ${ }^{9}$ Because HMOs ran their own health facilities and employed health practitioners, they were subject to additional legal requirements set out in the Medical Practitioners and Dentists Act (Chapter 253 of the Laws of Kenya) and had to be licensed both by the Commissioner of Insurance and the Medical Practitioners and Dentist Board.

\section{The impact of private health insurance}

The impact of private health insurance is assessed in light of the government's goal to provide affordable, accessible and equitable health care of good quality to all citizens. These dimensions, as well as the

${ }^{9}$ Brokers are defined as "an intermediary concerned with the placing of insurance business with an insurer or reinsurer for or in expectation of payment by way of brokerage, commission for or on behalf of an insurer, policy-holder or proposer for insurance or reinsurance and includes a health management organization ...”. See Section 2(1), Insurance Amendment Act 2006. 
externalities of the private health insurance sector, are explored in the following sections.

\section{Timely access to bealth care}

Access to health care is problematic for many people due to the lack of adequate health facilities and equipment and the poor road network and infrastructure. It is questionable whether private health insurance can address these access barriers, especially for people living in rural areas. Moreover, because private health facilities are not evenly distributed throughout the country, private health insurance cannot guarantee the insured equitable access to health care services.

\section{Improving financial protection}

Given Kenya's low per person income (about US\$1410 a year in 2015; Government of Kenya, 2016) and high poverty levels, particularly among people living in rural areas, the majority of the population cannot afford to buy private health insurance. Annual premiums range from US\$524 (UAP insurance) to US\$894 (Avenue Healthcare) for a comprehensive family policy (covering principal, spouse and child) with defined benefits (see Table 10.5), putting it well beyond the reach of all but the richest households. The fact that private health insurance requires lump-sum annual payments rather than smaller monthly payments makes it even less affordable for the poor. It is only the NHIF and a few community-based insurance schemes (for example, Kinga ya Mkulima insurance cover for small-scale tea farmers) that allow monthly payments of their premiums.

\section{Improved revenues to health facilities}

Patients with private health insurance do not leave hospital without paying their hospital bill, which allows health facilities to recuperate costs. Musau (1999) confirms that all health facilities accredited to treat privately insured patients experienced improved revenues compared with those that are not accredited to do so. Health facilities are also used more effectively when they partner with private health insurance providers, especially those that were formerly under-used. However, anecdotal evidence provides examples of fraudulent behaviour, where health facilities collude with policy-holders against insurance companies, 


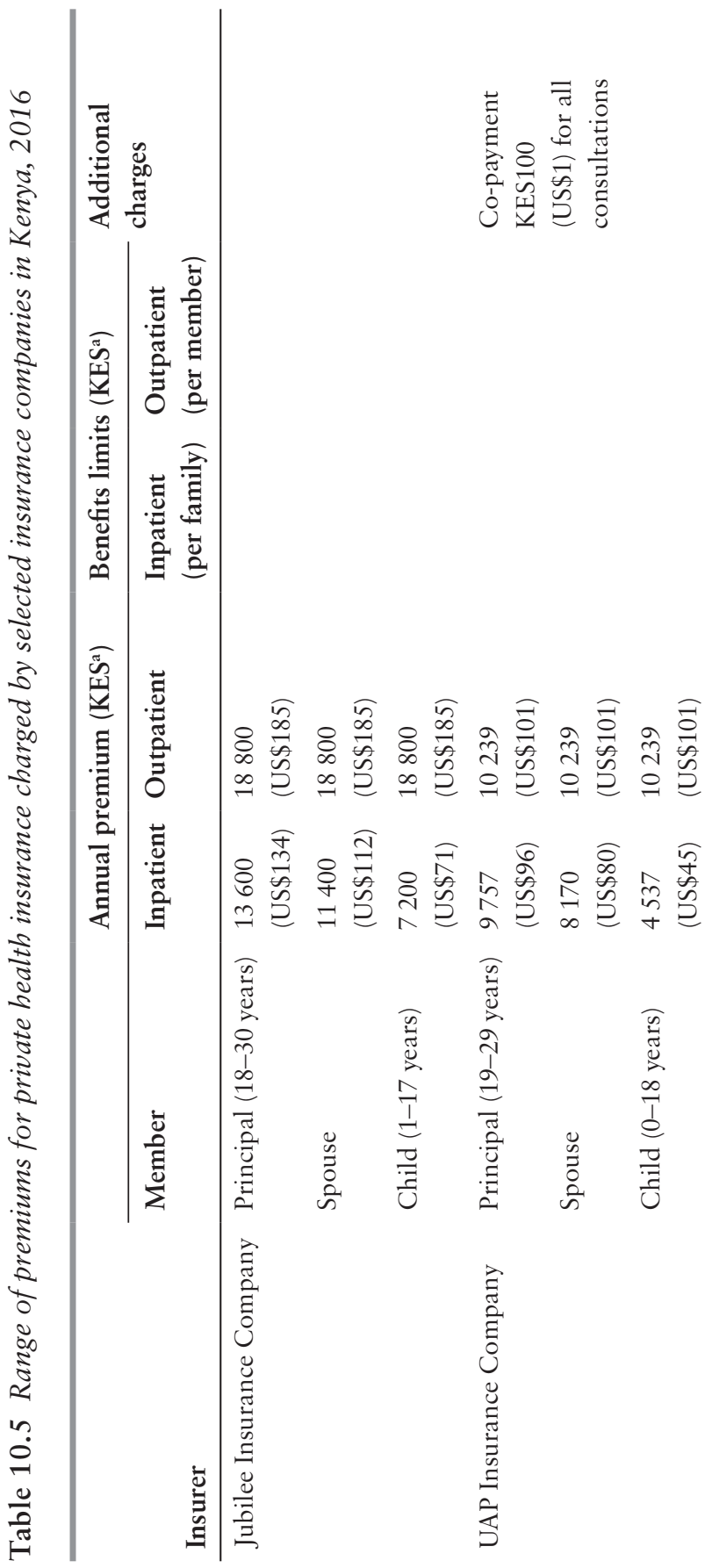




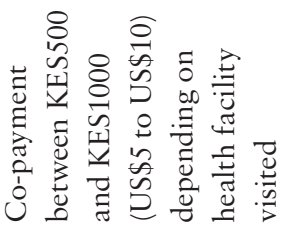

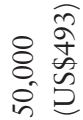

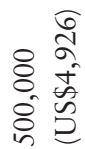

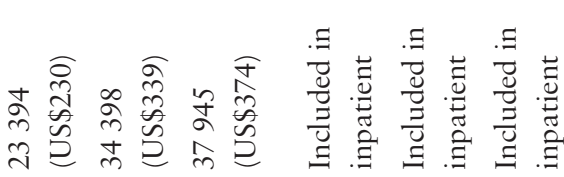

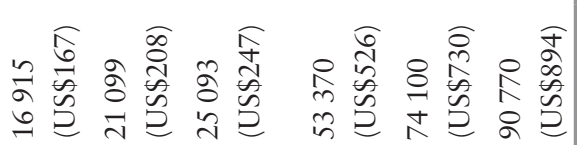

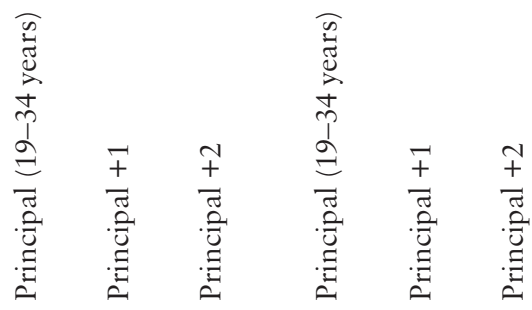

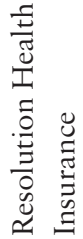

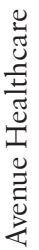


or where accredited facilities lodge fake reimbursement claims causing revenue losses to the insurance company.

The impact of private health insurance on the publicly financed health system

The growth of the private health care market is thought to have exacerbated inequalities in access to health care. After the introduction of the cost-sharing programme in 1989 the private sector became an alternative for people able to pay higher fees for a better quality of care. As the private health insurance market has grown, there has been a migration of health professionals from public to private facilities, eroding human resources in the public sector and contributing to the poor quality of services in public facilities. Private providers contracted by private health insurance companies have been able to attract good health workers by offering better pay and a good working environment. This trend has been a major cause for concern due to its negative impact on quality in public facilities and on health care inequalities. It is estimated that only 600 out of 5000 registered doctors work in public health facilities, with the rest working in private establishments at home or abroad (Siringi, 2001). Given that most health professionals work in urban centres, this adds to the urban-rural divide in terms of access to private health insurance and quality health services.

\section{Barriers to the expansion of private health insurance}

The private health insurance market is very small in Kenya, both in terms of contribution to total and private spending on health and in terms of population coverage. The vast majority of private spending on health comes from out-of-pocket payments (WHO, 2018). Uptake of private health insurance is low because the population is poor, most health professionals and facilities are located in urban areas (Kimani, Muthaka \& Manda, 2004) and health insurance schemes usually target urban centres and the formal sector. In 2015, employment in the formal sector accounted for only about $17.2 \%$ of total employment (Government of Kenya, 2016). Private health insurance companies tend to focus their marketing efforts on low-risk individuals (Kimani, Muthaka \& Manda, 2004), so private health insurance is often regarded as a service for the middle or upper classes. Finally, the credibility of 
private health insurance companies has been low in recent years, with illegal practices and poor financial management leading to the closure of several medical insurance companies; fraudulent activities have also been carried out by the insured.

In spite of these significant barriers to expansion, the private health insurance industry has some potential to grow in future, especially if mechanisms are put in place to ensure quality and affordability. Private insurers could reduce premium prices by encouraging groups to enrol or by paying more attention to how providers deliver health services - for example, specifying the use of generic medicines and adherence to clinical guidelines. Fraud and mismanagement could be minimized through improved regulation and oversight. To address the issue of affordability for individuals, premiums could be made payable in monthly instalments rather than in annual lump-sum payments (see Box 10.1).

\section{Box 10.1 Affordable private health insurance scheme by Kenya Women Finance Trust}

In 2008, the Kenya Women Finance Trust launched a cheap health insurance product that targets members of cooperative societies, social clubs and investment groups. The scheme offers inpatient care, personal accident and funeral cover for KES3600 per year (approximately US\$35) and allows monthly payments. It also uses a health identity card and offers family rather than individual cover to address concerns about fraud and adverse selection.

The Kenya Women Finance Trust is a large national microfinance institution that provides microfinance to low-income female entrepreneurs. Information about the organization and its health insurance cover is available at www.kwft.org.

\section{Conclusions}

The promotion of affordable and equitable access to health care is a major challenge in Kenya. The government, development partners and the private sector all play significant roles in addressing this challenge. Private health insurance supplements publicly financed coverage, but mainly focuses on households living in urban centres, where most quality 
health facilities are concentrated, exacerbating inequalities in access. However, even if health care facilities were more evenly distributed across the country, the expansion of private health insurance would still be limited by the high levels of poverty in rural areas. Thus, the pace with which private health insurance can expand in future is likely to be dictated by the speed with which poverty is reduced.

At the same time, health insurers need to design products that are more affordable to the poor and do more to raise public awareness of and confidence in the sector and to educate people about the benefits of health insurance. This is especially important because many Kenyans either do not understand the idea of insuring against risks or believe insurance is a service reserved for the rich.

Fraud and financial mismanagement have been major challenges for private insurers. Better use of information technology and smart card technology might help to reduce fraud, although information technology infrastructure is lacking in many rural areas, so this could only be used effectively in urban centres. The government also needs to ensure that there is adequate regulation in place to provide consumers with effective protection. Public policies used to be inadequate and poorly enforced, but current policy on insurance seems to be conducive to the expansion of private health insurance and to promoting government goals for the health sector. Care is needed, however, to ensure that the health insurance system is designed in a way that promotes equitable access to health care and does not undermine quality and accessibility for those who rely on publicly financed services.

\section{References}

AKI (2016). Insurance industry annual report 2015. Nairobi, Association of Kenya Insurers.

Chee G, Tharmaratnam V (1997). AAR Health Services - Kenya: final evaluation report, July 1995-July 1997. Arlington, VA, Promoting Financial Investments and Transfers to Involve the Commercial Sector in Family Planning (PROFIT) (submitted to USAID/Office of Population Family Planning Services Division).

Consumer Information Network (2006). Bridging the health financing gap in Kenya: tough choices for a struggling nation. CIN Briefing Paper No. 8/2006. Nairobi, Consumer Information Network.

Government of Kenya (2010). Facts and Figures 2010. Nairobi, Ministry of Medical Services. 
Government of Kenya (2016). Economic survey 2016. Nairobi, Kenya National Bureau of Statistics, Government Printer.

Kenya National Bureau of Statistics (2007). Basic report on well-being in Kenya, based on Kenya Integrated Household Budget Survey 2005/06. Nairobi, Kenya National Bureau of Statistics.

Kimalu PK et al. (2004). A review of the health sector in Kenya. Working Paper Series 11/2004. Nairobi, Kenya Institute for Public Policy Research Analysis. Kimani DN, Muthaka DI, Manda DK (2004). Healthcare financing though bealth insurance in Kenya: the shift to a National Social Health Insurance Fund. Kenya Institute for Public Policy Research and Analysis Discussion Paper No. 42. Nairobi, Kenya Institute for Public Policy Research and Analysis. KIPPRA (Kenya Institute for Public Policy Research and Analysis) (2010) Kenya Economic Report 2010: Enhancing sectoral contribution towards reducing Poverty, unemployment and inequality in Kenya. Nairobi, Kenya Institute for Public Policy Research and Analysis.

McCord MJ, Osinde S (2002). MediPlus health services: notes from a visit July 2002. Memphis, TN, The Microinsurance Centre.

Ministry of Health (1999). Kenya National Health Accounts 1994. Nairobi, Ministry of Health, Department of Planning, and Ministry of Health, Partnerships for Health Reform.

Ministry of Health (2003). Kenya Household Expenditure and Utilization Survey report 2003. Nairobi, Ministry of Health.

Ministry of Health (2005). Kenya National Health Accounts (2001-2002). Nairobi, Ministry of Health.

Ministry of Health (2007). Facts and figures at a glance: health and healthrelated indicators 2006. Nairobi, Ministry of Health, Division of Planning.

Ministry of Health (2009). Kenya Household Expenditure and Utilization Survey report 2007. Nairobi, Ministry of Health.

Ministry of Health (2013). Transforming Health: Accelerating Attainment of Universal Health Coverage: The Kenya Health Sector Strategic and Investment Plan (KHSSP) July 2014-June 2018. Nairobi: Ministry of Health.

Ministry of Health (2014). 2013 Kenya Household Health Expenditure and Utilization Survey. Nairobi, Ministry of Health.

Ministry of Health (2015a). Kenya National Health Accounts 2012/13. Nairobi, Ministry of Health.

Ministry of Health (2015b). Health Facts and Figures 2014. Nairobi, Ministry of Health.

Musau SN (1999). Community-based health insurance: experience and lessons learned from East Africa. Technical Report No. 34. Partnerships for Health Reform Project. Bethesda, MD, Abt Associates, Inc. 
Muthaka DI, Kimani DN, Mwaura S, Manda DK (2004). A review of the regulatory framework for private healthcare services in Kenya. Discussion Paper Series 35/2004. Nairobi, Kenya Institute for Public Policy Research Analysis (KIPPRA).

National Hospital Insurance Fund (2016). Customers: www.nhif.or.ke/ healthinsurance/customers; accessed on 14/11/2016.

Onsomu E, Muthaka D, Mwabu G, Nyanjom O, Dutta A, Maina TM, Barker C, and Muchiri S (2014). Public Expenditure Tracking Survey in Kenya, 2012 (PETS-Plus). Washington, DC: Futures Group, Health Policy Project; and Nairobi, Kenya: Kenya Institute for Public Policy Research and Analysis.

Siringi S (2001). Kenya government promised to increase doctor's salaries to curb brain drain. Lancet, 358(9278):307.

WHO (2018). Global Health Expenditure Database; http://apps.who.int/nha/ database/Select/Indicators/en; accessed on 15/01/2018. 